\title{
Correction to: LKM-AMI: A Lightweight Key Management Scheme for Secure two Way Communications between Smart Meters and HAN Devices of AMI System in Smart Grid
}

\author{
Vinod Kumar $^{1} \cdot$ Rajendra Kumar $^{2}$ - S. K. Pandey ${ }^{3}$ \\ Published online: 19 November 2020 \\ (C) Springer Science+Business Media, LLC, part of Springer Nature 2020
}

Correction to: Peer-to-Peer Netw. Appl.

https://doi.org/10.1007/s12083-020-00921-6

The original version of this article unfortunately contained mistakes.

The PDF version contained unconverted mathematical symbols which are correctly displayed in the html version.

The original article has been corrected.

Publisher's note Springer Nature remains neutral with regard to jurisdictional claims in published maps and institutional affiliations.

The online version of the original article can be found at https://doi.org/ 10.1007/s12083-020-00921-6

\footnotetext{
Vinod Kumar

vk@allduniv.ac.in

1 Department of Electronics and Communication (Computer Science \& Engineering), University of Allahabad, Allahabad, UP, India

2 Department of Computer Science, Jamia Millia Islamia, New Delhi, India

3 Ministry of Electronics \& Information Technology (Government of India), New Delhi, India
} 